\title{
The Linkage Development Between Tourism and Media Industries
}

\author{
Liu Yiming ${ }^{1}$, Zhang $\mathrm{Bo}^{2}$, Li Shuang ${ }^{3}$ \\ ${ }^{1}$ Hotel Management School, University of Jinan, Jinan, China, 250002 \\ ${ }^{2}$ Hotel Management School, University of Jinan, Jinan, China, 250002 3Hotel Management School, \\ University of Jinan, Jinan, China, 250002
}

Keywords: Linkage, Tourism, Media, Development

\begin{abstract}
This thesis starts from the analysis of industry chain and mode circle, the analysis of interact role and dissection of joint-action mechanism to analysis mechanism of integrated development in our county's tourism and media industry by synthesis, especially to summary and explore the mechanism of industry's interactive development, so that can prove a feasible measure for the two industries to develop better jointly.
\end{abstract}

\section{Introduction}

As tourism and media industries' rapid grow their linkage development feature has been shown obviously. Currently experts and industry insiders focus on this hot issue. The research has been carried on about how to get better interaction effect to develop these two industries and to realize the industrialization.

\section{The analysis of industry chain and mode circle}

The basic of the interactive development between our country's tourism and media industry are the similarity and inclusiveness of the two industries. Tourism is a comprehensive industry including "Food, Accommodation, Transportation, Travel, shopping and Entertainment", which needs support and transmission of information. So it needs media industry to play a role as medium; Media industry is a traditional industry which needs to revitalize, enhance its function and variety ceaselessly. It needs a powerful support to unchain its passive status. That means it needs tourism to improve its economic performance. Before the effective interactive development between tourism and media industry, we should analyze the relationship of the two industry's supply chain in all directions. as shown in the Fig.1.

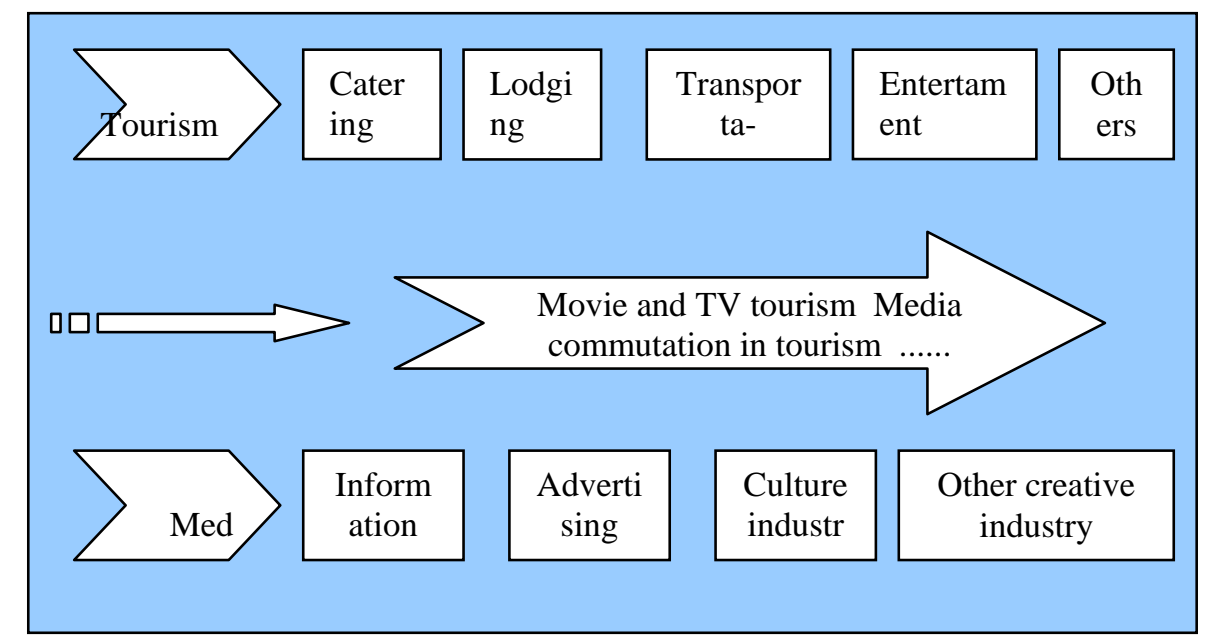

Fig. 1 The analysis of industry chain of tourism and media industry

Pardon and complementation of industry chain From the analysis of Fig.1,we can see that the industry chain of tourism mainly includes catering ,lodging, transportation, entertainment ect, 
The .media industry is combined by entertainment, information ,advertising ect.,Many industries on the two industry chain is mutual inclusive and mutual supplementary. For example: Entertainment industry is both included in the two industries. The development of the lodging industry needs publicize and support of advertisements, Information industry can improve its own interests by entertainment, it also can set up media communications in tourism.

The penetrative support of industry's model circle Shown as Fig.1, Tourism and media industry are interpenetrate in industry chain and development of the interests. As they are bit and new born industries, the inside and outside condition that can influence these two industries are basically the same, there are also many similarities on the direction and mode of development. These all determine the mode circle of tourism and media industry is interlaced and penetrative. Meanwhile, it provides a moment of linkage and integral development.

\section{The analysis of interactive role}

The effective position of tourism to media industry. The best example of the combination of tourism and media industry is The Travel Channel, It is the most representative product of the combination of tourism and media industry in China, It is also a pioneer of media tourism.

Analyzing from the success of the Travel Channel, we can summarize the affection of tourism to media industry to the following points.

(1) Tourism can provide artistic inspiration to the development of media industry The products of our country's media industry are all from life and go beyond it, Tourism is a kind of activity that is close to our life style can proved many materials to the product of media industry. From the example shown above, the materials of The Travel Channel are all come from the luxuriant tourist resources in Hainan province, the luxuriant tourist resources prove the artistic products which are from life and go above life to the development of The Travel Channel.

(2) The development of media industry is leech on to the spiritual substance and cultural connotation of tourism. The products of media industry represented by film, video and Advertising .The substance they showed are mostly publicized and show the given connotation and essence. The tourism in Hainan province is carrying the function of heritage and purifies culture. Showing the local customs and the advanced idea related to environment protection while showing the tropical flavor of Hainan province The example which is shown above has point out that the Travel Channel was a human landscape channel at first, now it has expanded into an entertainment and leisure program, but any program's found and development must attach to local leisure, entertainment and local customs

(3) Tourism will leads more service business integrate with media industry The development of tourism has brought the development of some related industries. In some ways it has improved and changed the industrial structure, provide more jobs and derived many industries, these industries is deriving from media industry step by step. Now many areas included Hainan province appears a phenomenon that many grand hotels and vacation village are investing to films and TV dramas, extending much service industry, or taking part in more social benefits by media. For example Pretty Lady in The Travel Channel has helped the poor areas and disaster areas by donation and charity performance, behaved in a social responsible way, lead the development direction for many service business.

The media industry's influence on tourism. According to statistics, since the release of Dae Jang Geum in 2005, the tourist who goes travel to the South Korea has increased nearly 15\% than 2004. Dae Jang Geum was attracting tourists from all over the world to experience the culture and landscape of South Korea. Moreover, music, trapping and other entertainment industries are developing swiftly, which are attracting tourists from all over the world to visit this country of fashion and trend.

Analyzing from the succeed of Dae Jang Geum, we can include the affect of media industry to tourism to the following points. 
(1) Tourism depends on the development and progress of media industry With the development of social economy, popular and entertaining is the trend of our county's tourism, Now, internet, television and other mass media is penetrating into our entertainment lifestyle, .Moreover, television, broadcast, film and other audiovisual media is flooding in every where in our life. This kind of popular and common form is influencing every tourist

(2) Media industry is deeply influencing tourism management Nowadays, media communications is dividing into advertising media, news media marketing, media delivery, mass media , create and perform, come down to many territory like international trade, law, advertising, psychology, tourism and so on. In this era, information is developing swiftly, the pulsating movement of intellectual management and new economy should be chased by public. Meanwhile, tourism is developing mutually by cross-enterprise collaboration, like build the movie studios, developing the publication of tourism, expend the marketing and profession all-wave. The management part is getting closer to media development. The two industries are developing and coordinating synchronously, meanwhile, their management is related.

\section{Analysis of joint-action mechanism}

The joint-action of the two industries is upgraded, the interacts are deeper and deeper. The old town of Lijiang has cooperated with film and video, their joint-action is deeper and deeper. The old town of Lijiang has been cited as national AAAAA scenic spot by National Tourism Administration in 2001. Recently, tourism and business are developing swiftly, it release many program with local culture like Naxi ancient music and Lishui Sands. Especially many different kinds of serials and operas like LuBan Lurao, One-meter Sunshine and Zhuan Shan etc. The tourism of ancient city of Lijiang has spurred the media industry at first, then the two industries has promoted each other and consistent with each other. That brings the new upsurge of local social economy's swift development. This is a typical represent of our country's tourism and media industry's joint-action goes from explore to step-down and finally reached the upgrade of interactive.

Explore of mechanism of interactive development. Analyzing the current situation of our county's tourism and media industry, it can be seen that their joint-action needs support and coordination of many industries. It must start from globalism of the whole system, and arrange the development mechanism generally. Basic on the facts and comprehensive study, Author have summarized the joint-action of our country's tourism and media industry

The joint- action of out country's media industry and tourism should be guided by government, jointed by guild and public, so that can make sure the two industries and joint-act industry can allaround, coordinated and sustainable development, This joint-action is an industry chain cored by tourism and media industry grow up and develop with the compete, support, linkage and permeate of each other. Government should build a logical platform for the joint-action, with the great effort of guild and public, guide by the method of advanced mass media. Coordinate the development and trend of new-born tourism industies, build reasonable joint-action and perfect the development countermeasure of the industries.

\section{Conclusion}

The joint-action of tourism and media industry in our country needs effort of both sides, the two industries should regain the initiative, and communicate more. Now, the demonstrate of the two industries' joint-action's research is still at its primary stage. So, the following points that should be paid attention to

The joint-action of tourism and media industry is the common development direction of the two industries, so, the development of the two industries should be valued fully, and the steps of their development should be the same. Don't be unable to attend to everything at one time. The end-all of the joint -action should be achieved their economic profit, do not ignore culture's spread and inherit. 
The two industries should share and assume social responsibility. The two industries' joint-action should follow the public policy, live in the tide and set reasonable goals

\section{Acknowledgements}

This work was financially supported by the Shandong Planning office of Philosophy and Social Science Foundation (12CJJZ04), the Humanities and Social Science Planning Foundation of Shandong Province, China (2014RKB019AC),Jinan Planning office of Philosophy and Social ScienceFoundation(12BGI37),Preresearch of National Social Science Fund by University of Jinan(1 4YY09),Project of teaching research by School of Hotel Management, University of Jinan(JYXM0 03-2014), and the PH.D Foundation of University of Jinan (XBS1349).

\section{References}

[1] EileenR.Meehan.Tourism, Development,and Media. Springer Science Business Media 2008.6.20

[2] Meethan K. Place, image and power: bright on as resort in the tourist image: myths and myth making in tourism[M] .Selwyn,ed,Chichester:Wiley,1996:180-196

[3] Shandong Tour Information website. http://www.sdta.cn/dtss

[4] Baidu::http://baike.baidu.com/view/3495347.htm\#1

[5] National Tourism Office wibesite:http://www.cnta.gov.cn/ 